\title{
TROCA E RECIPROCIDADE EM MERCADOS DE PROXIMIDADE: UMA REFLEXÃO A PARTIR DE ESTUDO DE CASO NO SERTÃO DO CEARÁ ${ }^{1}$
}

\author{
Maria Odete Alves* \\ Marcel Bursztyn ${ }^{* *}$ \\ Suely Salgueiro Chacon
}

\section{RESUMO}

Este artigo apresenta uma reflexão sobre a configuração dos mercados de proximidade. Em particular, observa a articulação que acontece entre troca e reciprocidade, a partir da análise das diversas formas de comercialização de produtos agropecuários originários da comunidade Lagoa dos Cavalos (município de Russas, sertão do Ceará). O objetivo é identificar se, apesar do avanço do capitalismo mercantil em certas regiões rurais, como no semiárido nordestino, os agricultores familiares continuam baseando suas estratégias de reprodução social em relações não-mercantis. A análise tomou como base teórica a reinterpretação de Granovetter para embeddedness (enraizamento da economia), a contribuição de Wilkinson sobre os mercados de proximidade e a teoria da reciprocidade de Temple. A análise adota a abordagem qualitativa e combina o uso de fontes testemunhais, documentais e bibliográficas. $\mathrm{Na}$ definição dos atores entrevistados, utilizou-se a amostragem não probabilística intencional. As conclusões apontam que os produtos são vendidos em mercados inscritos em circuitos coincidentes com a rede de proximidade, onde troca e reciprocidade coexistem e se articulam, complementando-se uma à outra.

Palavras-chave: Troca. Reciprocidade. Mercados de proximidade. Semiárido brasileiro.

\section{INTRODUÇÃO}

O utilitarismo adquiriu tal dimensão na sociedade contemporânea que se torna difícil ao indivíduo imaginar a circulação de bens e serviços sem que haja o interesse. No entanto, os indivíduos não agem somente em função de seus próprios interesses, mas também visando ao vínculo social. Godbout (1999, p. 39) explica que “As coisas estão muitas vezes a serviço dos vínculos, mesmo nos casos de reciprocidade similares à equivalência mercantil".

É mais fácil perceber a existência desses princípios em regiões rurais, pois apesar do avanço do capitalismo mercantil, os agricultores prosseguem fundamentando suas estratégias de reprodução social em relações não-mercantis. Em estudos realizados no semiárido

\footnotetext{
${ }^{1}$ Este artigo aprofunda aspectos apresentados na tese de doutorado Mercado, arame e Estado: recursos comuns e resistência em Lagoa dos Cavalos no sertão do Ceará, defendida em 2012 pela primeira autora, no $\mathrm{CDS} / \mathrm{UnB}$.

* Doutora em Desenvolvimento Sustentável pelo Centro de Desenvolvimento Sustentável/UNB; pesquisadora do Escritório Técnico de Estudos Econômicos do Nordeste/BNB. E-mail: moalves1@gmail.com.

** Doutor em Desenvolvimento Econômico e Social, professor do Centro de Desenvolvimento Sustentável, Universidade de Brasília - CDS/UNB. Brasília, Brasil.

*** Doutora em Desenvolvimento Sustentável e Professora da Universidade Federal do Cariri, Juazeiro do Norte, CE, Brasil.
} 
brasileiro, autores como Sabourin $(1999,2001$ c, 2009, 2010) têm demonstrado a existência desses princípios entre agricultores familiares.

$\mathrm{Na}$ verdade, um dos primeiros estudiosos a se debruçar sobre o tema foi Karl Polanyi. Em sua obra A Grande Transformação, publicada em 1944, o cientista propôs a noção de embeddedness ("enraizamento da economia"). Ao analisar a gênese da sociedade capitalista, Polanyi (2000 [1944]) contestou a transformação de terra e trabalho em mercadoria, por entender que isso é contrário à natureza humana, já que nem todo trabalho desenvolvido pelo homem visa ao lucro. Segundo ele, apesar de os mercados terem estado quase sempre presentes em todas as sociedades pré-capitalistas, nenhuma delas jamais teve sua economia totalmente controlada por eles. No seu entender, as regras e os costumes da sociedade delimitavam a esfera da economia e mudanças ocorreram somente no século XIX, com o advento do mercado autorregulador.

No entender de Polanyi, a economia seria uma invariante histórica, sendo o mercado apenas um dos seus princípios. O autor identificou formas múltiplas de produzir e distribuir riquezas nessas sociedades, as quais se conjugam com diferentes regimes e se associam a cada tempo e lugar, obedecendo aos princípios: mercado autorregulado, redistribuição e reciprocidade.

Porém, alguns aspectos do pensamento de Polanyi são alvo de críticas de autores mais recentes, principalmente quando afirma que os princípios (ou formas de economia) da redistribuição e da reciprocidade teriam sido afetados após a implantação do capitalismo e do livre mercado. Na contemporaneidade, segundo Polanyi, à medida que se perdem valores humanos éticos e culturais, ambos estariam desaparecendo em prol da dominância do mercado autorregulado.

Uma das limitações da proposta de Polanyi seria a falta de clareza quanto à origem dos valores humanos por ele mencionados. Para Temple (1997, 2001), este seria o principal problema da teoria desenvolvida por Polanyi, sugerindo então, que tais valores são produzidos por relações de reciprocidade. Outra limitação diz respeito à afirmação de Polanyi sobre o desaparecimento da reciprocidade. Temple e autores como Sabourin (2006a) e Nicolas (2002) acreditam que a reciprocidade permanece no dia a dia das pessoas, mesmo em sociedades contemporâneas, coexistindo com a troca capitalista.

Apesar das limitações, a teoria de Polanyi prossegue alimentando as reflexões de autores atuais. Particularmente a distinção entre economia e mercado e as diferentes formas de intercâmbio por ele identificadas, foram incorporadas nas análises de estudiosos da 
sociologia econômica (WILKINSON, 2002). A noção de embeddedness originalmente proposta por Polanyi foi reinterpretada por Granovetter (1985), afirmando que o modo de funcionamento dos mercados é influenciado pelas redes sociais.

Este trabalho se insere no contexto acima apresentado, no qual se faz uma reflexão sobre a configuração dos mercados de proximidade. A partir da análise das formas de comercialização de produtos agropecuários oriundos de uma comunidade rural do sertão do Ceará (Lagoa dos Cavalos, Russas), observam-se as relações sociais que acontecem no âmbito da rede de proximidade, em particular, se coexistem as lógicas da troca e da reciprocidade e se elas se articulam entre si.

O texto está distribuído em quatro seções, além desta introdução e das considerações finais. Na primeira seção é apresentada a abordagem teórica e os procedimentos metodológicos. A segunda e a terceira seções discorrem sobre a base teórica utilizada na análise do caso, enquanto que a quarta apresenta o estudo de caso, numa discussão sobre a configuração dos mercados de proximidade, em particular, a articulação que acontece entre troca e reciprocidade, a partir da análise das diversas formas de comercialização de produtos agropecuários locais.

\section{PROCEDIMENTOS TEÓRICO-METODOLÓGICOS}

As análises aqui apresentadas tomaram como base teórica a reinterpretação de Granovetter para embeddedness. Os aportes teóricos de Wilkinson (2002) ajudaram a compreender a forma como a rede de proximidade influencia os mercados da agricultura familiar, enquanto que os de Temple (2003, 2004a, 2004b, 2004c, 2008, 2009) permitiram perceber o papel das estruturas de reciprocidade na produção de valores humanos que mantêm viva a rede.

A abordagem metodológica do estudo é qualitativa, por reconhecer nela as condições adequadas para a aproximação do objeto de pesquisa. Para coleta das informações, combinouse o uso de fontes testemunhais, documentais e bibliográficas. As informações de campo foram coletadas em duas etapas. Numa fase exploratória, com o uso de roteiros, entrevistaram-se atores aleatórios, servindo o conteúdo como base para a definição de atores que seriam entrevistados numa segunda etapa, utilizando-se da amostragem não probabilística intencional (COSTA NETO, 1977; MARCONI \& LAKATOS, 1990; COUTINHO, 2011).

No total, 24 atores foram entrevistados durante os meses de abril de 2009, abril, maio, junho e setembro de 2010 e maio de 2012. Os conteúdos foram analisados com o uso da 
técnica da triangulação de dados (TRIVIÑOS, 1987; CROLL, 1995; SOUZA; ZIONI, 2003), facilitando a compreensão do fenômeno a partir das diversas perspectivas e permitindo associarlconfrontar informações obtidas a partir das diversas técnicas, de modo a verificar coerência e consistência das informações.

\section{REDES SOCIAIS, MERCADOS DE PROXIMIDADE E RECIPROCIDADE}

A reinterpretação dada por Granovetter (1985) para a noção de embeddedness "enraizamento" originalmente proposta por Polanyi (2000 [1944]) sugere que o modo de funcionamento dos mercados é influenciado pelas redes sociais. Este autor conseguiu demonstrar como a ação econômica sofre um processo permanente de filtração pelas relações sociais nas quais está submersa.

Para Granovetter, a economia está enraizada em redes sociais e, portanto, o entendimento do comportamento econômico passa necessariamente pelo conhecimento da rede. Ainda, segundo Granovetter, existe uma ligação estreita entre o "enraizamento" da economia em redes sociais e a relação de confiança entre as pessoas, sentimento este que, segundo Temple (1997) nasce das relações sociais e tem como fundamento a reciprocidade, conforme análise apresentada a frente.

A partir dos trabalhos de reinterpretação de "enraizamento" de Granovetter (1985), Wilkinson (2002) analisou os mercados da pequena agroindústria, tipicamente informais e de proximidade. Com base em tal análise, Wilkinson sugeriu que esses mercados existem não simplesmente em função do reflexo da pobreza ou da falta de consciência do consumidor, mas devido à solidez do tecido social local. Wilkinson menciona algumas características inerentes aos mercados de proximidade:

$\checkmark$ Representam um prolongamento de relações familiares de forma direta (como consumidores) ou indireta (como canais de comercialização).

$\checkmark$ São coincidentes com a rede social.

$\checkmark$ Em função da imersão dos atores em determinados circuitos sociais, os conhecimentos existentes no interior das redes são simplesmente replicados.

$\checkmark$ A produção evolui em função da demanda, acarretando duas consequências importantes: a) o mercado não se coloca como problema; b) os produtores participantes da rede têm receio de buscar novos mercados, pois isso os obrigaria 
a ultrapassar a fronteira da rede social na qual estão inseridos, requerendo novos conhecimentos.

$\checkmark$ A relação estabelecida entre produtor e comprador é de confiança, razão pela qual o cliente crê na qualidade do produto, que adquire reputação, em geral dispensando a garantia formal.

$\checkmark$ Esses mercados são relativamente imunes a pressões externas (mercadológica, reguladora), em função de reputações e lealdades consolidadas pelas repetidas transações entre os mesmos atores, ligados por relações de parentesco, vizinhança, conhecimentos pessoais etc.

Tomando como base as características acima definidas, pode-se concluir que os mercados de proximidade funcionam no interior de redes sociais formadas por laços de parentesco e vizinhança. Esta forma de constituição das redes, baseada em laços de proximidade, lhes atribui outra característica importante, que é a de serem centradas na reciprocidade (SABOURIN, 2006b), que produz valores humanos como a amizade, o respeito, a confiança, a aliança, a responsabilidade e a reputação (TEMPLE, 1997, 2003; CAILLÉ, 1998, 2002a, 2002b). Tais valores são fundamentais na regulação das relações sociais, portanto, exercem o papel de consolidar os mercados de proximidade.

Reciprocidade, de acordo com Temple, significa

[...] a relação entre seres humanos que permite a cada um sofrer a ação da qual é simultaneamente o agente. Em termos de consciência de atuar e de sofrer, significa que a consciência de um redobra a consciência do outro, e que ambas se relativizam para engendrar uma consciência comum [tradução livre do espanhol] (TEMPLE, 2011b, p. 1).

Nessa perspectiva, reciprocidade se manifesta com a mesma lógica da dádiva como definida por Mauss (2003 [1950]): um princípio de regulação das relações sociais pela tríplice exigência de dar, receber e retribuir, e que resulta num conjunto infindável de prestações e contraprestações entre os indivíduos.

A reciprocidade é composta pelo que Temple (2004c, 2009) denominou de estruturas de reciprocidade binária (bilateral) e ternária (unilateral, bilateral, centralizada, compartilhada e generalizada).

$\mathrm{Na}$ estrutura binária, a relação pode acontecer entre indivíduos (face a face) ou grupos (coletiva) iguais ou desiguais (TEMPLE, 2004b) e dela se originam os sentimentos de amizade e a aliança. Os sentimentos de confiança e responsabilidade se originam na reciprocidade ternária, que envolve pelo menos três indivíduos numa cadeia de participantes, 
cada um atuando sobre outro e estando sujeito à ação de um terceiro, numa rede ou círculo, conforme descrito abaixo (TEMPLE, 2003, 2004a, 2004b, 2004c, 2008, 2009):

a) Se ela é unilateral, o participante doa por um lado e recebe pelo outro, fazendo surgir o sentimento de responsabilidade pelos demais.

b) Se ela é ternária bilateral, a dádiva faz um percurso de retorno pelo mesmo caminho de ida, contando com um intermediário entre os dois opostos, o qual está imbuído do sentido de responsabilidade que se transforma em sentimento de justiça por igualdade em relação a ambos aos que se localizam nos lados opostos.

c) Se ela é ternária centralizada (ou redistribuição), um único participante faz a intermediação entre os demais, surgindo uma estrutura em estrela. Essa estrutura gera nos demais atores um sentimento de confiança na justiça e na responsabilidade daquele que faz a intermediação. Porém, o sentimento de responsabilidade é unicamente de quem está no centro.

d) Se ela é ternária compartilhada (de partilha), apresenta uma estrutura em círculo, porém sem o intermediário central típico da reciprocidade centralizada. Cada um se dirige a todos, gerando o sentimento não exatamente de responsabilidade, pois não tem especificação particular. Esta estrutura é a matriz da confiança e nela se manifesta o sentimento coletivo "um por todos e todos por um", passando a ideia de totalidade.

e) Se ela é ternária generalizada (ou mercado de reciprocidade), conjugam-se as diversas estruturas mencionadas anteriormente sem que, no entanto haja a exclusão das relações típicas do intercâmbio.

Enfim, para Temple, mesmo admitindo a imposição cada vez mais frequente do sistema capitalista e do livre intercâmbio na vida das pessoas, em todas as sociedades permanecem estruturas de reciprocidade. No mundo contemporâneo, argumenta Temple (2004c), a reciprocidade ternária generalizada nada mais é que o resultado do estabelecimento de vários tipos de relações ternárias entre as famílias, seja positiva ou negativa. As possibilidades de manifestação dessa estrutura de reciprocidade aumentam proporcionalmente ao aumento da concentração populacional e da diferenciação das atividades humanas.

Finalmente, o conjunto das estruturas de reciprocidade é responsável pela relação social. Elas podem se articular entre si ou não, visto que é possível haver autoexclusão em função de incompatibilidade de umas com as outras (TEMPLE, 2003, 2009). Entretanto, é a 
articulação entre as diversas estruturas de reciprocidade que permite aos indivíduos pertencerem a diversas delas.

\section{TROCA E RECIPROCIDADE EM MERCADOS DE PROXIMIDADE}

Da mesma forma que auxilia na análise dos mercados da pequena agroindústria, a definição de mercados de proximidade de Wilkinson (2002) ajuda no entendimento do funcionamento dos mercados em que é comercializada grande parte dos produtos originários da agricultura familiar. A afirmativa de Wilkinson (2002) de que os mercados da pequena agroindústria persistem em função do seu "enraizamento" no tecido social pode ser estendida aos principais mercados da agricultura familiar.

Outro aspecto a ressaltar é que a noção de "enraizamento" adotada na proposta de Wilkinson não é incompatível com a ideia de Temple (2008) de que em tais mercados ocorre o entrecruzamento de relações de reciprocidade de vários tipos. Desta forma, pode-se entender que troca e reciprocidade coexistem nesses mercados.

De fato, estudos realizados por Nicolas (2002) e Sabourin (2006a) mostram que, apesar de antagônicas, troca e reciprocidade coexistem no dia a dia das pessoas, mesmo em sociedades contemporâneas. Assim, o "enraizamento" dos mercados de proximidade nas redes sociais permite-lhes serem espaços ricos para a observação da articulação entre troca e reciprocidade.

Mas qual a diferença entre troca e reciprocidade?

A distinção proposta por Temple (2004 apud SABOURIN, 2006b, p. 218) para os termos troca e reciprocidade ajuda na compreensão do significado de cada uma: "A operação de intercâmbio [troca] corresponde a uma permutação de objetos, enquanto a estrutura de reciprocidade constitui uma relação reversível entre sujeitos”. Ainda, na troca os indivíduos buscam satisfazer interesses pessoais, ignorando a existência ou a possibilidade de criação de laço social; na reciprocidade, ao contrário, o indivíduo revela preocupação com o outro, portanto esta última não é redutível a um interesse particular ou à permuta de objetos (TEMPLE, 1997; NICOLAS, 2002; SABOURIN, 2006a).

Se a reciprocidade é baseada na lógica da dádiva, pode-se pensar que ela também se origina em função da vontade de construir laços (valor das pessoas) ou das próprias necessidades da coletividade (SABOURIN, 2006c) e não pela utilidade dos bens (valor de uso) ou em função de seu valor monetário (valor de troca) (MAUSS, 2003 [1950]). Portanto, reciprocidade não significa a simples troca, mas representa um sistema aberto (dar-receber- 
retribuir), na verdade um elemento fundador da sociabilidade, específico para cada tempo e lugar (TEMPLE, 1983).

O fato é que troca e reciprocidade coexistem no cotidiano das pessoas e podem se manifestar complementando-se uma à outra ou de forma paralela e dissociada e até mediante tensões, formando sistemas mistos, dependendo de como acontece a articulação entre uma e outra (NICOLAS, 2002; SABOURIN, 2006a). No entanto, a imposição do sistema de intercâmbio nas sociedades rurais, de forma sistemática e progressiva, tem contribuído para que muitas vezes se confunda reciprocidade com troca (SABOURIN, 2006a).

Sabourin (2011, p. 40) sugere que a análise da articulação entre troca e reciprocidade deve considerar três modalidades, sem perder de vista que são possíveis diversas configurações intermediárias: justaposição de mundos paralelos; complementaridade reversível; contradição de lógicas. Ainda, segundo o mesmo autor, a contradição de lógicas leva a conflitos, provocando a paralisia de ambas ou o domínio de uma sobre a outra.

No próximo item analisa-se o processo de comercialização dos produtos oriundos da comunidade Lagoa dos Cavalos, no sertão do Ceará, de modo a identificar a coexistência e articulação entre troca e reciprocidade nesses mercados.

\section{O ESTUDO DE CASO}

O sertão nordestino é um território profícuo para a realização de testes empíricos da Teoria da Reciprocidade de Temple (1997, 2001, 2003, 2004a, 2004c, 2008, 2009, 2011). Estudos realizados nesse território têm demonstrado que relações de reciprocidade de vários tipos se entrecruzam nos mercados de proximidade (SABOURIN, 1999, 2001a, 2001b, 2001c, 2008, 2009; SABOURIN; MARINOZZI, 2000). Ou seja, em suas estruturas variadas, a reciprocidade está presente - e se articulando com a troca - nas diversas formas de comercialização utilizadas pelos agricultores familiares dessa região, como é o caso de Lagoa dos Cavalos, objeto de estudo neste item.

\section{a. Aspectos sociais e econômicos}

O termo Lagoa dos Cavalos é utilizado para definir o conjunto de quatro comunidades rurais interligadas fisicamente (Lagoa dos Cavalos, Córrego Salgado, Junco e Barbatão), cuja trajetória de desenvolvimento comum tem sido mediada por uma associação comunitária local. Localiza-se à margem do rio Jaguaribe e ao lado do Perímetro Público de 
Irrigação Tabuleiro de Russas, a 22 km da sede do município de Russas, que por sua vez dista 160 km de Fortaleza, capital do estado do Ceará (Figura 1).

Figura 1 - Localização da área de estudo

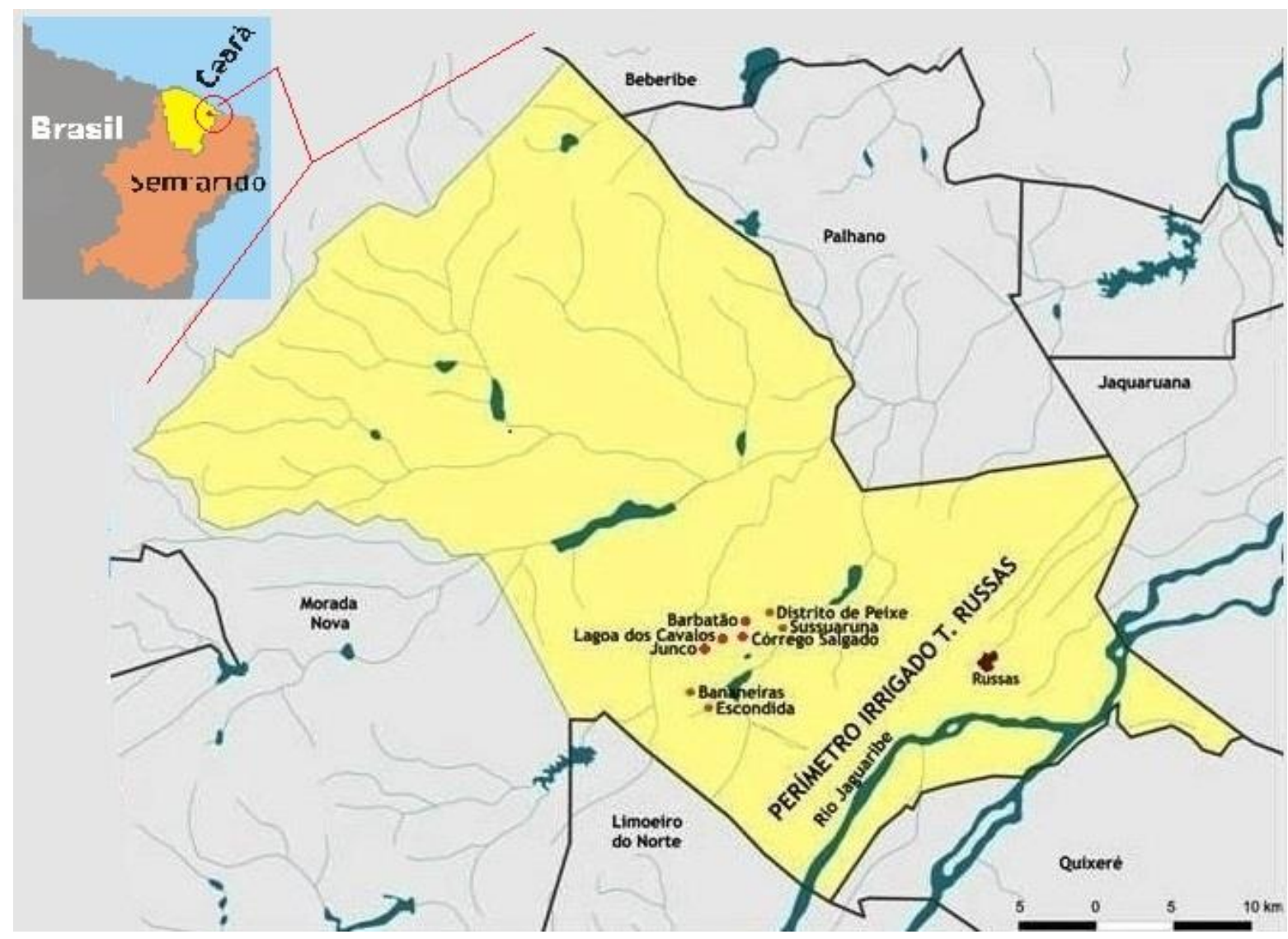

Fonte: ETENE-BNB, a partir de dados do IBGE (Instituto Brasileiro de Geografia e Estatística).

A população de Lagoa dos Cavalos soma 280 habitantes (distribuídos em 79 famílias), com uma média de 3,54 pessoas por domicílio, sendo 1,77 homens e 1,77 mulheres.

A Comunidade se caracteriza pela formação de uma rede social de proximidade com fortes laços entre moradores, principalmente por parentesco (Figura 2), mas também por amizade, compadrio e vizinhança.

A população de Lagoa dos Cavalos conta com 74,3\% em idade economicamente ativa e $88,6 \%$ de alfabetizados, sendo superior o percentual entre as mulheres $(92,9 \%$ alfabetizadas contra $84,3 \%$ de homens e $11,5 \%$ de chefes de família). 
Figura 2 - Árvore Genealógica da Comunidade Lagoa dos Cavalos

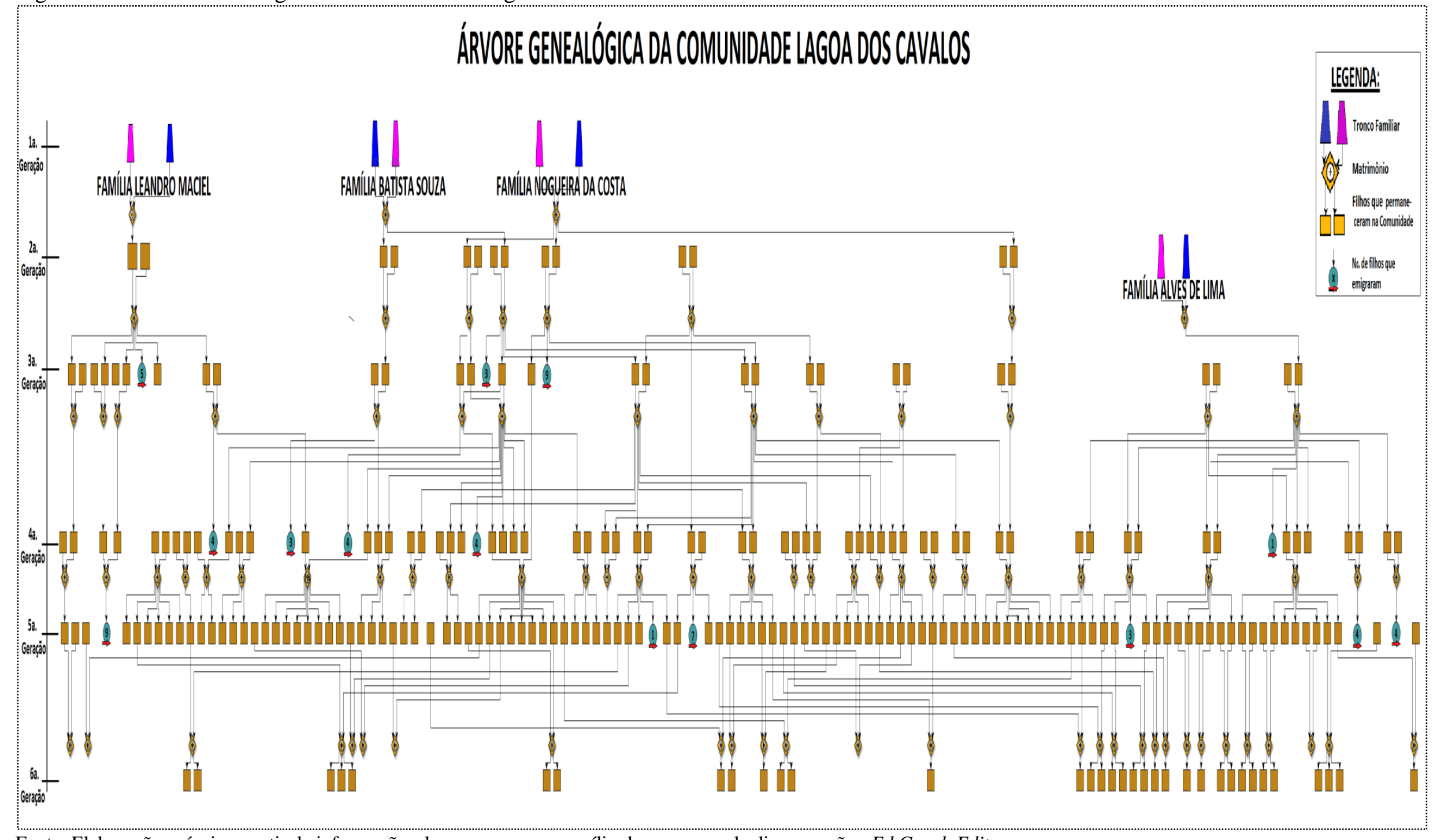

Fonte: Elaboração própria a partir de informações de campo, com o auxílio do programa de diagramação yEd Graph Editor.

Ciência e Sustentabilidade - CeS | ISSN 2447-4606 v. 1, n. 1, p. 132-153, jul/dez 2015141 
Quanto à ocupação produtiva, a Comunidade se caracteriza como pluriativa, seguindo a regra geral do sertão nordestino (ALBALADEJO, 1999; ALVES, 2002; ALVES et. al. 2006; CARNEIRO, 2008). Mesmo assim, a prática da agricultura ainda é preponderante entre os moradores $(82,3 \%)$, face aos $17,7 \%$ que exercem atividades não-agrícolas. Destacamse, entre as atividades agrícolas: coleta da castanha de caju e extração de pó cerífero da carnaúba; plantio de feijão, milho, mandioca e hortaliças; criação de abelhas, galinhas caipiras, suínos, ovinos e bovinos.

Verifica-se, assim, que Lagoa dos Cavalos é uma comunidade na qual a maioria das atividades está voltada para a (e é dependente da) agricultura. As dificuldades na prática dessas atividades existem e são importantes, a começar pela limitação na produção agropecuária, devido principalmente à elevada fragmentação da terra. Sobre esse aspecto, vale mencionar que a Comunidade conta com 19 imóveis rurais distribuídos nos 817 hectares, dos quais 17 têm área entre 1 e 30 hectares. Na média, existem 10,3 hectares por domicílio familiar na Comunidade (817 hectares/79 famílias). No entanto, 550 hectares desta área pertencem a uma única propriedade (terras de herança) compartilhada por 13 famílias. Enquanto nesse imóvel a área média por família é de 42,32 hectares (550 hectares/13 famílias), nas demais cai para 4,07 hectares por família (269 hectares/66 famílias).

Portanto, somado a outros fatores limitantes como a dificuldade de acesso a água, a crédito e a assistência técnica, o reduzido tamanho das propriedades é um dos motivos que levou os agricultores de Lagoa dos Cavalos, a partir de determinado momento de sua história, a adotarem algumas estratégias de reprodução social para continuar viabilizando a produção.

Desde meados dos anos 1980, o eixo central das estratégias tem sido a adoção da ação coletiva no desenvolvimento da maioria dos trabalhos produtivos locais. A partir da experiência da formação de um grupo produtivo informal (Grupo de Produtores), em 1986, outros se criaram e se formalizaram tendo como guarda-chuva a associação comunitária local. Desde então, permanecem alguns grupos, sendo mais representativos os de apicultura, ovinocultura e da casa de sementes. Esses grupos são marcados por características peculiares, quais sejam: a composição envolve somente membros da rede de proximidade, o tamanho é reduzido (variando de 6 a 19 membros) e o funcionamento é regulado pelos próprios participantes, que ao longo de sua existência criam, modificam e adaptam regras e modos de trabalhar, na medida das necessidades impostas pela dinâmica social e de produção. 
Como ilustração, apresentam-se dois diagramas (Figuras 3 e 4), nos quais aparecem as relações de parentesco dentro dos Grupos de Apicultura e de Ovinocultura. No Grupo de Apicultura (Figura 3), não existe uma única pessoa sem vínculo de parentesco com pelo menos outro membro. Do total de 19 associados, 13 têm entre cinco e 11 laços de parentesco com os demais.

Figura 3 - Relações de parentesco entre membros do Grupo de Apicultura

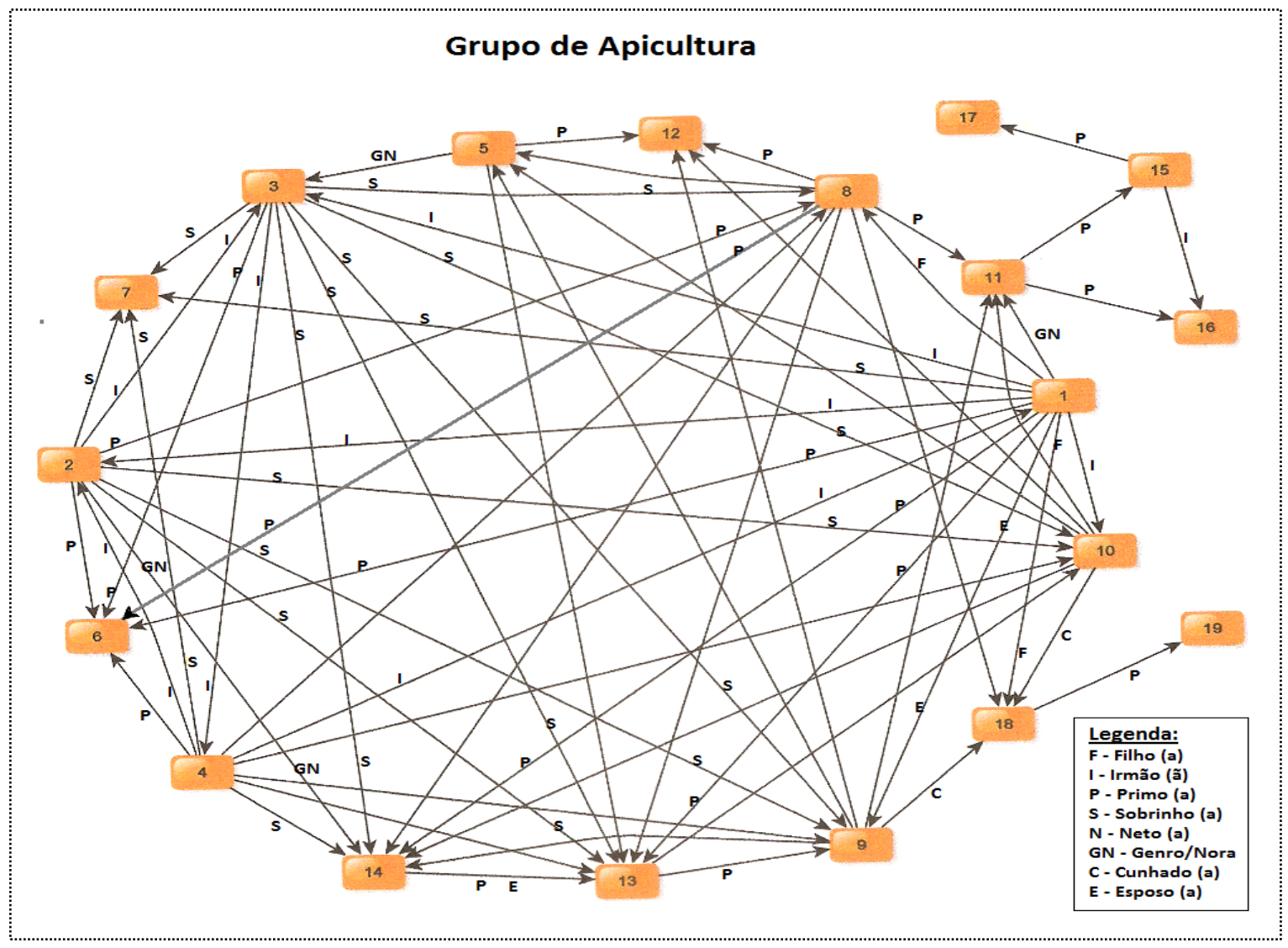

Fonte: Elaboração própria a partir de informações de campo, com o auxílio do programa de diagramação $y E d$ Graph Editor.

A formação do Grupo de Ovinocultura ainda é mais restrita, na medida em que este abriga apenas seis participantes, todos com vínculo estreito de parentesco: irmãos, filhos, sobrinhos e primos (Figura 4). 
Figura 4 - Relações de parentesco entre membros do Grupo de Ovinocultura

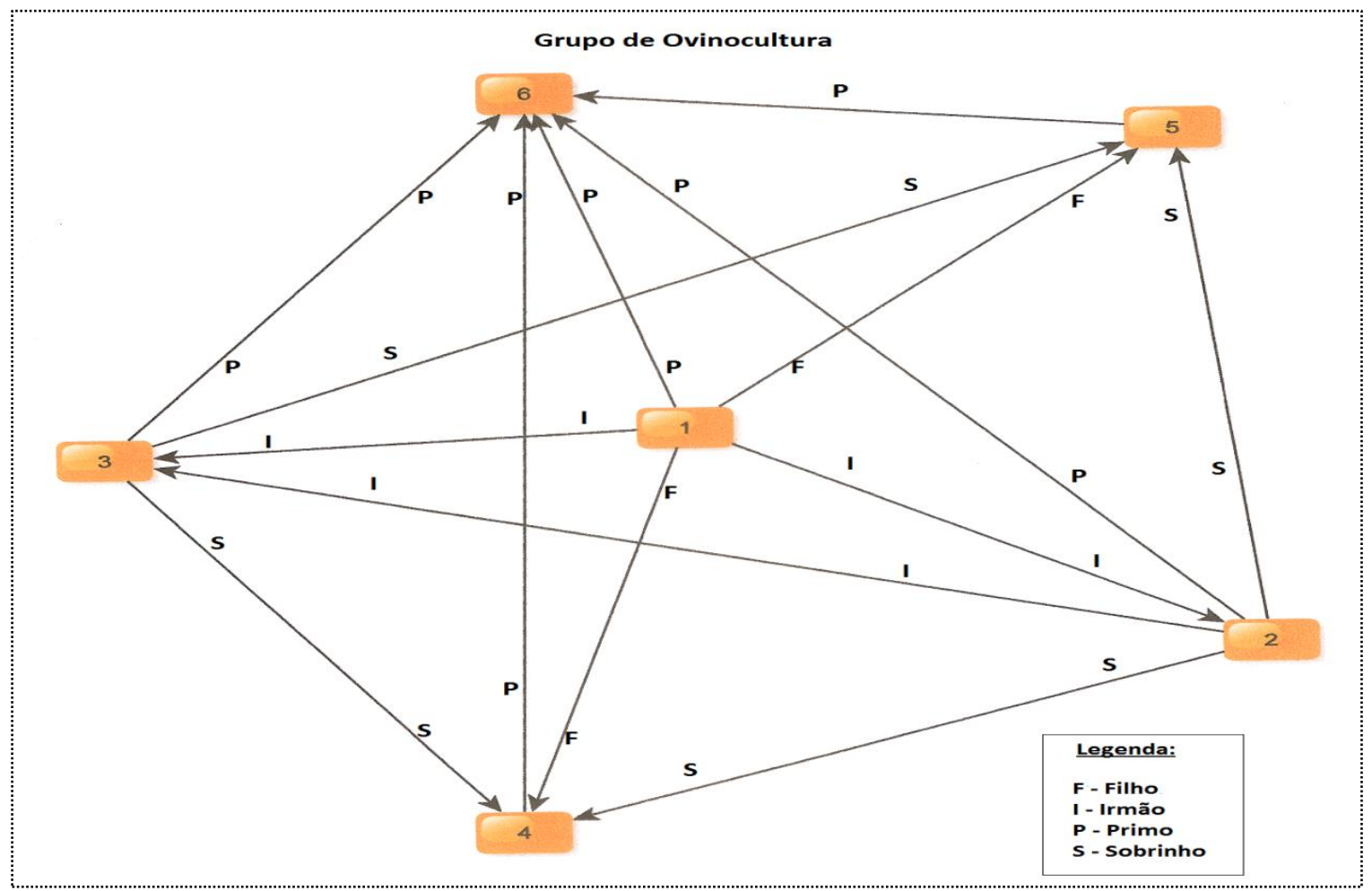

Fonte: Elaboração própria a partir de informações de campo, com o auxílio do programa de diagramação $y E d$ Graph Editor.

As estratégias de comercialização, assim como acontece no processo produtivo acima mencionado, são engendradas dentro da rede de proximidade, mais precisamente, nos mercados de proximidade. Esta é a discussão apresentada no item a seguir.

\section{b. Produtos comercializados e funcionamento dos mercados de proximidade}

O fato de a grande maioria dos agricultores de Lagoa dos Cavalos se dedicar a atividades agropecuárias não significa que sua produção seja pouco diversificada, pois se trata de estratégia para minimizar riscos e manter a segurança alimentar com autonomia. Neste sentido, observa-se em geral, que algumas atividades têm o objetivo principal de suprir as necessidades básicas de alimentação da família, seguindo para o mercado somente o excedente, como é o caso dos produtos milho, feijão e mandioca. Outros produtos têm dupla função, sendo parte direcionada para o consumo familiar e parte para o mercado, exemplo das aves (galinhas caipiras), carnes ovina, suína, bovina, e do leite bovino e derivados. Produtos voltados exclusivamente para o mercado são a castanha de caju, o pó cerífero da carnaúba e o mel de abelhas. 
Assim, deve-se entender que parte dos produtos a seguir tratados como comercializáveis são também, em maior ou menor grau, destinados ao autoconsumo. A decisão do agricultor sobre o que se destina totalmente ou em parte ao autoconsumo ou ao mercado, é dependente da realidade específica e particular de cada família, porquanto acontece no âmbito da unidade familiar.

Obedecendo a esse princípio é que o excedente dos produtos individuais sazonais (representados principalmente por feijão e farinha de mandioca) e as aves (galinhas caipiras) são vendidos na própria Comunidade e na feira livre que funciona na Sede de Russas. Tanto no mercado local quanto na feira livre, deve-se considerar que os atores participam de um circuito social específico (WILKINSON, 2002), facilitando a manifestação da reciprocidade binária face a face, o que tende a fortalecer os laços de proximidade dentro da própria rede.

Sobre a feira livre, vale salientar que é um dos principais canais de comercialização utilizados pelos agricultores nordestinos e se inclui no leque de estratégias de reprodução, conforme revelam alguns estudos apontados por Ribeiro (2007). Ela é um dos espaços que mais dão vida aos mercados de proximidade pois, mais que um ponto de compra e venda de produtos, é um evento social. É um espaço de criação, manutenção ou reprodução de sociabilidade e de manifestação de identidades, porque nela acontecem os negócios, os encontros, as articulações políticas e sociais. Tudo isso contribui para a ampliação da rede de proximidade e, por consequência, para o fortalecimento das relações de reciprocidade entre agricultores e destes com os consumidores. Assim, a relação direta estabelecida entre vendedor e consumidor, no dia a dia da feira, fortalece as estruturas de reciprocidade, em particular a binária face a face.

Quanto ao mel de abelhas, existe a produção coletiva (Grupo de Apicultura) e a produção individual. Pequena parte da produção (coletiva e individual) é vendida no mercado local (Comunidade); outra parte vai para a Bodega Nordeste Vivo Solidário, em Aracati ${ }^{2}$, enquanto que a maior parte (cerca de $70 \%$ ) é entregue a um intermediário que leva para o mercado externo, principalmente Alemanha.

Quando a venda do mel de abelhas é no local, os processos são semelhantes àqueles já apontados em relação à venda do excedente dos produtos sazonais individuais e galinhas caipiras. Ocorrem dentro de um circuito social no âmbito da rede de proximidade, envolvendo

\footnotetext{
${ }^{2}$ A Bodega Nordeste Vivo e Solidário, de Aracati, da qual são associados os agricultores de Lagoa dos Cavalos, foi inaugurada em 2004 e faz parte da Rede Bodegas, uma criação da Cáritas. Essa Rede atua sob regime associativo, sendo espaço para exposição e venda dos produtos a preços justos, assim como para a capacitação dos agricultores. Na Bodega de Aracati, além do mel de abelhas, são vendidos outros produtos orgânicos e artesanais.
} 
uma relação direta entre produtor e consumidor, pouco diferindo do que acontece na feira, a não ser pelo fato de que, dentro da Comunidade é maior a possibilidade de existirem laços de parentesco entre os atores. Neste sentido, percebe-se o mercado interno à Comunidade como um prolongamento das relações familiares, conforme apontado por Wilkinson (2002).

Já a porção do mel comercializada por intermédio da Bodega não permite uma relação direta (face a face) entre produtor e consumidor, na medida em que o trânsito das informações entre os opostos é feito por um intermediário. Neste caso, se manifesta uma estrutura de reciprocidade ternária bilateral, em que a informação entre vendedor e comprador retorna pelo mesmo percurso de ida, com a intermediação de um terceiro, em princípio imbuído da responsabilidade pela qualidade do que leva e traz: o consumidor obtém informações sobre o fornecedor e a qualidade do produto; o fornecedor recebe indicações sobre as exigências do consumidor em relação ao produto. Trata-se de uma estrutura de reciprocidade que gera confiança, responsabilidade e reputação do produtor em relação ao intermediário e vice-versa. A proposta de remuneração privilegiada para o produtor tem em sua base os sentimentos de justiça e equidade o que, de certa forma, supriria o vácuo na relação direta entre produtor e consumidor, instituído pela intermediação (SABOURIN, 2006a). Assim, mesmo que de forma indireta, e a distância, se criariam relações e laços entre atores que antes não interagiam.

Os animais ovinos destinados ao mercado são vendidos em pé, para abate e para cria. Mesmo no caso da produção coletiva (Grupo de Ovinocultura), os animais são comercializados de forma individual, principalmente na venda direta na própria Comunidade, para moradores locais e para comunidades circunvizinhas. A exemplo dos excedentes e da porção do mel vendidos dentro da própria Comunidade, essas modalidades de troca proporcionam o contato direto entre produtor e consumidor, criando a possibilidade de geração e/ou fortalecimento de laços de fidelidade, confiança, reputação e até amizade, originários da reciprocidade binária. Este foi um dos motivos pelos quais o grupo realizou comercialização coletiva somente enquanto pagava as parcelas do financiamento que possibilitou a aquisição dos animais ${ }^{3}$.

No âmbito desse Grupo, os animais iniciais foram adquiridos por intermédio de financiamento, com prazo máximo de carência fixado em dois anos, quando então deveriam ser pagas parcelas mensais até a quitação do empréstimo. Com isso, impôs-se a necessidade

\footnotetext{
${ }^{3}$ A Cáritas assessorou os agricultores em relação à elaboração de um projeto para criação de ovinos e financiou os animais, no ano de 1998.
} 
de arrecadar, mesmo que temporariamente, uma quantia elevada que permitisse honrar o compromisso financeiro assumido com o órgão financiador. Como consequência, seria necessário obter economia de escala, fazendo com que os agricultores optassem pela venda coletiva a compradores não pertencentes à rede de proximidade.

Até então, o Grupo acumulava entre 40 e 50 animais e os vendia a um único comprador. Esse modo de comercialização representava alguns problemas para os agricultores. Por um lado, o mercado deixava de ser um prolongamento das relações familiares e ultrapassava a fronteira do circuito social habitual, impondo a necessidade de estabelecer novos laços de confiança e de lidar com novos atores e novas regras. Por outro, deixava uma lacuna em relação ao provimento dos consumidores locais, cuja demanda por pequenos animais era insatisfeita, porém distribuída durante todo o ano. Ou seja, diante da realidade local, ao invés de concentrar uma grande quantidade de abate em determinado período, seria mais coerente fornecer pequenas quantidades ao longo de todo o ano.

Sobre o segundo problema, vale transcrever o argumento de um agricultor local ao se referir ao negociante externo, no qual afirma que "[...] comprava tudo de uma vez e levava pra fora", contrariando sua vontade de "remediar" a Comunidade. Ou seja, o agricultor informante não se sentia à vontade ao entregar sua produção a consumidores externos, em detrimento das famílias locais que necessitavam daquela provisão, demonstrando um sentimento de responsabilidade em relação às famílias da Comunidade. O agricultor-vendedor está envolto numa rede de proximidade que proporciona a manifestação de estruturas de reciprocidade ternária, levando o participante a receber por um lado e doar por outro e, desta forma, imbuir-se daquele sentimento de responsabilidade.

A saída da situação desconfortável aconteceu logo que o Grupo concluiu o pagamento das parcelas do empréstimo, pois a partir desse momento, os membros decidiram realizar a comercialização de forma individual.

Ao firmar o acordo de comercialização individual, o grupo resolveu os problemas anteriormente mencionados, na medida em que, por um lado garantiu a liberdade de ação (autonomia) dos sócios quanto ao momento e quantidade de animais a abater e vender. Por outro, livrou-se da trabalheira da negociação com o mundo exterior. Como lembra Wilkinson (2002), esses agricultores estão imersos em circuitos sociais mais ou menos fechados, significando, na prática, que têm uma compreensão muito imediata do mercado (RIBEIRO, 1994), desconhecendo suas regras, normas e especificações. Além disso, do ponto de vista desses agricultores, manter a venda no mercado local (mercado de proximidade) se configura 
como uma forma de fortalecer os laços de proximidade e, por consequência, a manifestação de estruturas de reciprocidade que produzem valores humanos como responsabilidade, confiança e reputação.

\section{CONSIDERAÇÕES FINAIS}

Este artigo analisou as diversas formas de comercialização de produtos agropecuários numa comunidade rural do sertão do Ceará (Lagoa dos Cavalos, Russas), inseridas em mercados de proximidade. Buscou-se identificar as lógicas de troca e reciprocidade nas relações que movem tais mercados e se existe articulação entre ambas.

A análise tomou como base teórica a reinterpretação de Granovetter para embeddedness (enraizamento da economia), segundo o qual a economia está enraizada em redes sociais e, portanto, a forma como funcionam os mercados depende da configuração de tais redes. Os aportes teóricos de Wilkinson ajudaram a compreender a forma como a rede de proximidade influencia os mercados da agricultura familiar, enquanto que os de Temple permitiram perceber o papel das estruturas de reciprocidade na produção de valores humanos que mantêm viva a rede.

Lagoa dos Cavalos é formada por uma extensa rede de proximidade, composta essencialmente de parentela e vizinhança. Os produtos são vendidos principalmente em mercados locais: na própria unidade de produção (para amigos, parentes, vizinhos, mercearias locais e intermediários), na feira livre e nas mercearias da sede municipal. A produção local, realizada em pequena escala, é comercializada sob demanda, adaptando-se às distintas expectativas dos compradores. Tais mercados estão inscritos na rede de relações sociais e, portanto, o processo de troca é filtrado pelo conjunto das relações que acontecem nesses espaços locais de venda.

Desta forma, a comercialização dos produtos de Lagoa dos Cavalos acontece dentro de um circuito social restrito que permite a articulação com estruturas de reciprocidade, principalmente a face a face, que envolve a relação direta entre vendedor e comprador. No caso do mel de abelhas, a venda abrange também consumidores fisicamente mais distantes, por intermédio da Rede Bodega Nordeste Vivo Solidário, numa estrutura de reciprocidade ternária bilateral.

Por estarem inscritos na rede de proximidade, tais mercados são socialmente controlados. A percepção de qualidade dos produtos oferecidos, por exemplo, foge 
completamente aos padrões das exigências sanitárias legais, pois os parâmetros adotados são os da confiança e da reputação. Neste sentido, pressões sofridas pelos mercados locais informais para adaptarem-se à atual legislação sanitária podem representar uma ameaça ao seu "enraizamento", uma vez que tal legislação afeta o seu modo de funcionamento.

Finalmente, é perceptível a coexistem entre troca e reciprocidade nos mercados nos quais são comercializados os produtos de Lagoa dos Cavalos. As lógicas se articulam e se complementam nas relações que acontecem no âmbito da rede de proximidade. Assim, os mercados de proximidade, além de um espaço que assegura a comercialização dos produtos locais, funciona como instrumento de manutenção e fortalecimento das estruturas de reciprocidade na Comunidade.

\section{REFERÊNCIAS}

ABRAMOVAY, R. Entre Deus e o diabo: mercados e interação humana em ciências sociais. Tempo Social: Revista de Sociologia da USP, v. 16, n. 2, p. 35-64, 2004.

ALBALADEJO. C. Réflexions sur la notion de "systèmes locaux de connaissance" a partir de projets de recherche/formation et développement en Amérique Latine. In: Elaboration de références technico-économiques, Montpellier, Cirad Tera, septembre 1999, 12p.

ALMEIDA, A. W. B. de. Terras de preto, terras de santo, terras de índio: uso comum e conflito. In: GODOI, E. P. de; MENEZES, M. A. de; MARIN, R. A. (Orgs.). Diversidade do campesinato: expressões e categorias, v. 2: estratégias de reprodução social. São Paulo: Editora UNESP; Brasília, DF: NEAD, 2009. pp. 39-66.

ALVES, M. O. Pluriatividade como estratégia de sobrevivência no sertão nordestino: o caso de Tejuçuoca, Ceará. Raízes, v. 21, n. 01, pp. 114-121, Campina Grande, UFCG/PPGS, jan./jun.2002.

ALVES, M. O; VALENTE JUNIOR, A. S.; BRAINER, M. S. de C. P. Pluriatividade no espaço rural do pólo Baixo Jaguaribe, Ceará. Fortaleza: Banco do Nordeste do Brasil, 2006. (Série Documentos do Etene, v. 11).

CAILLÉ, A. Nem holismo nem individualismo metodológicos: Marcel Mauss e o paradigma da dádiva. Revista Brasileira de Ciências Sociais, São Paulo, v. 13, n. 38, 1998. Disponível em: <http://www.scielo.br/scielo.php?script=sci_arttext\&pid=S010269091998000300001\&lng=en\&nrm=iso>. Acesso em: 23 maio 2008.

O princípio da razão, o utilitarismo e o antiutilitarismo. Revista Sociedade e Estado, Brasília, v. 26, n. 1-2, p.26-56, 2002a.

A dádiva das palavras: o que dizer pretende dar. In: MARTINS, P. H. (Org.). A

dádiva entre os modernos: discussão sobre os fundamentos e as regras do social, Petrópolis: Vozes2002b. p. 99-135. 
CARNEIRO, W. M. A. Pluriatividade na agricultura familiar: o caso do pólo de desenvolvimento de agronegócios cariri cearense. Fortaleza: Banco do Nordeste do Brasil. 2008 (Série Documentos do ETENE, v. 22).

COSTA NETO, P. L. Estatística. São Paulo: Blücher, 1977.

COUTINHO, C. P. Metodologia de investigação em ciências sociais e humanas: teoria e prática. Coimbra: Almedina, 2011.

CROLL, P. La observación sistemática en el aula. Madrid: Muralla, 1995.

GODBOUT, J. T. O espírito da dádiva. Tradução por Patrice Charles F. X. Wuillaume. Rio de Janeiro: Editora Fundação Getúlio Vargas, 1999.

GRANOVETTER, M. S. Economic action and social structure: problem of embeddedness. American Journal of Sociology, Chicago, v. 91, n. 3, p. 481-510, nov., 1985. Disponível em: $<$ https://www2.bc.edu/ jonescq/mb851/Feb26/Granovetter_AJS_1985.pdf $>$. Acesso em: 20 set. 2015.

MARCONI, M. A.; LAKATOS, E. M. Técnicas de pesquisa. 2. ed. São Paulo: Atlas, 1990.

MAUSS, M. Ensaio sobre a dádiva: forma e razão da troca nas sociedades arcaicas. In:___ Sociologia e antropologia. São Paulo: Cosac Nayfi, 2003. p. 183-314.

NICOLAS, G. o dom ritual, face velada da modernidade. In: MARTINS, P. H. (Org.). A dádiva entre os modernos: discussão sobre os fundamentos e as regras do social. Petrópolis: Vozes, 2002. p. 32-62.

POLANYI, K. A grande transformação: as origens de nossa época.1 ed. 1944. Tradução por Fanny Wrobel. 2. ed. Rio de Janeiro: Elsevier, 2000.

RIBEIRO, E. M. Fé, produção e política. São Paulo: Edições Loyola, 1994. . A pesquisa nas feiras: histórico e técnicas. In: RIBEIRO, E. M. (Org.). Feiras do Jequitinhonha: mercados, cultura e trabalho de famílias rurais no semi-árido de Minas Gerais. Fortaleza: Banco do Nordeste do Brasil, 2007. (Coleção BNB Projetos Sociais, 1). pp.83-112.

SABOURIN, E. Práticas de reciprocidade e economia de dádiva em comunidades rurais do Nordeste brasileiro. Raízes, Ano 18, n. 20, nov. 1999. p. 41-49.

. Aprendizagem coletiva e construção social do saber local: o caso da inovação na agricultura familiar da Paraíba. Estudos, Sociedade e Agricultura, v. 16, abril. 2001a. p.1340 .

. Estratégias coletivas e lógicas de construção das organizações de agricultores no Nordeste semi-árido. Antropolítica, n.9, Rio de Janeiro, UFF, 2001b. Disponível em: $<$ http://afm.cirad.fr/documents/3 Organisations/CD AFM/textes/439.pdf $>$. Acesso em: 27 set. 2011. 
. Reciprocidad e intercambio en comunidades campesinas del Nordeste: Massaroca (Bahia, Brasil). Revista Ibero Americana de Autogestión Y Acción Comunal, n. 35-36-37, 2001c, p. 101-112.

. Mudanças sociais, organização dos produtores e intervenção externa. In: CARON, P.; SABOURIN, E. (Eds.). Camponeses do sertão: mutação das agriculturas familiares no Nordeste do Brasil. Brasília: Embrapa Informação Tecnológica, 2003. pp.145-178.

Organizações e dispositivos coletivos dos agricultores familiares no Nordeste do Brasil. In: SABOURIN, E. (Org.). Associativismo, cooperativismo e economia solidária no meio rural. Brasília: Centro de Estudos Avançados Multidisciplinares, Núcleo de Estudos Avançados. v. 6. n. 23. 2006a. p. 29-61.

Práticas sociais, políticas públicas e valores humanos. In: A diversidade da agricultura familiar. Sérgio Schneider (Org.) Porto Alegre, UFRGS, Estudos Rurais, 2006b. p.215-239.

Interação entre ação coletiva e ação pública no manejo de recursos comuns no Nordeste do Brasil. Anais ... CONGRÈS INTERNATIONAL DES AMÉRICANISTES, ICA 52, Séville, 23-27 juillet 2006c. Disponível em:

<http://www.iddri.org/iddri/telecharge/forets/americanistes_seville_juil06_progr.pdf >. Acesso: 25 set. 2011.

A reciprocidade e os valores éticos da solidariedade econômica. In: CONGRESSO BRASILEIRO DE SOCIOLOGIA. 1, Anais... Recife, 2007.

Interação entre os dispositivos coletivos e institucionais dos agricultores e políticas públicas de desenvolvimento rural. In: II COLÓQUIO AGRICULTURA FAMILIAR E DESENVOLVIMENTO RURAL. Painel 2: Práticas de Desenvolvimento Rural: da criatividade dos agricultores às inovações político-instituionais. Anais... Porto Alegre, 2008.

. Camponeses do Brasil: entre a troca mercantil e a reciprocidade. Traduzido do francês por Leonardo Milani. Rio de Janeiro: Garamond, 2009.

. Teoria da Reciprocidade e sócio-antropologia do desenvolvimento. Sociologias, Porto Alegre, v.13, n. 27, p. 24-51, maio./ago. 2011.

Manejo dos recursos comuns e reciprocidade: os aportes de Elinor Ostrom ao debate. Sustentabilidade em Debate, Brasília, v. 1, n. 2, p.143-158, jul/dez. 2010. Disponível em: $<$ http://seer.bce.unb.br/index.php/sust/article/view/1689/1311>. Acesso em: 08 nov. 2011.

SABOURIN, E.; CARON, P. Camponeses e fundos de pasto no Nordeste da Bahia. In: GODOI, E. P. de; MENEZES, M. A. de; MARIN, R. A. (Orgs.). Diversidade do campesinato: expressões e categorias, v. 2: estratégias de reprodução social. São Paulo: Editora UNESP; Brasília, DF: NEAD, 2009. pp. 89-115. 
SABOURIN, E; MARINOZZI, G. Recomposição da agricultura familiar e coordenação dos produtores para a gestão de bens comuns no Nordeste brasileiro. Revista Econômica do Nordeste, Fortaleza, v. 31, n. 4, p.1008-1017, out-dez. 2000.

SOUZA, D. V de; ZIONI, F. Novas perspectivas de análise em investigações sobre meio ambiente: a teoria das representações sociais e a técnica qualitativa da triangulação de dados. Saúde e Sociedade, v. 12, n. 2, p. 76-85, jul-dez. 2003.

TEMPLE, D. La dialéctica del Don. 1983. Disponível em: $<$ http://dominique.temple.free.fr/reciprocite.php?page $=$ reciprocidad_2\&id_article $=150>$. Acesso em: 26 mar. 2012.

L'économie humaine. La revue du M.A.U.S.S. semestrielle, n. 10, $2^{\circ}$ semestre 1997. (Paris, La Découverte). Disponivel em:

$<$ http://mireille.chabal.free.fr/ecorecip.htm\#ancre605725>. Acesso em: 15 out. 2011.

. Le príncipe marché de réciprocité. Conference de l'association Cauris. 2001.

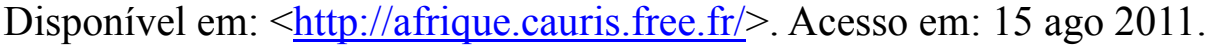

Las estructuras elementales de la reciprocidad. La Paz (Bolívia): Plural Editores, 2003.

Las estructuras elementales de la reciprocidad. Seminario sobre La reciprocidade - las estructuras elementales y las tres formas de la reciprocidad - Parte II. 2004a. Disponível em: $<$ http://dominique.temple.free.fr/reciprocite.php?page $=$ reciprocidad_2\&id_article $=454>$. Acesso em: 09 out. 2011.

EI mercado y La reciprocidad generalizada. 2004c. Disponível em: TEMPLE, D. La valeur dans le système Aymara. 2004b. Disponível em: $<$ http://dominique.temple.free.fr/reciprocite.php?page=reciprocite_2\&id_article $=189>$. Acesso em: 11 abr. 2011.

. La constitución boliviana y sus desafios. Revista Iberoamericana de Autogestión y Acción Comunal (RIDAA), n. 52-53-54, ano 26, Madrid, 2008, pp. 33-50 y pp. 51-76. Disponível em: $<$ http://dominique.temple.free.fr/reciprocite.php?page $=$ reciprocidad $2 \&$ id article $=83>$. Acesso em: 31 out. 2011.

. As origens antropológicas da reciprocidade. Jornal do Mauss, 2009. Disponível em: $<\mathrm{http}$ //www.jornaldomauss.org/periodico/wpcontent/uploads/2009/04/temple_origensantropologicasdareciprocidade.pdf $>$. Acesso em : 08 out. 2011.

O homem nu: valores constituídos ou matrizes do valor? Revista de Estudos Antiutilitaristas e Poscoloniais, 2011. Tradução por Eric Sabourin. pp. 1-6. Disponível em: $<$ http://dominique.temple.free.fr/reciprocite.php?page $=$ reciprocidad 2\&id article $=290>$. Acesso em: 07 nov. 2011. 
Reciprocidad. 2011b. Disponível em:

$<$ http://dominique.temple.free.fr/reciprocite.php?page $=$ reciprocidad\&id rubrique $=3>$. Acesso em: 30 out. 2011.

TRIVIÑOS, A. N. S. Introdução à pesquisa em ciências sociais: a pesquisa qualitativa em educação. São Paulo: Atlas, 1987.

WILKINSON, J. Sociologia econômica, a teoria das convenções e o fortalecimento dos mercados. Revista Ensaios (FEE), Porto Alegre, v. 23, n. 2, 2002. Disponível em:

$<$ http://revistas.fee.tche.br/index.php/ensaios/article/viewFile/2042/2424>. Acesso em: 13 nov. 2011. 